\title{
Effects of T-82, a New Quinoline Derivative, on Cholinesterase Activity and Extracellular Acetylcholine Concentration in Rat Brain
}

\author{
Kazuo Isomae ${ }^{1, *}$, Masago Ishikawa ${ }^{1}$, Megumi Ohta ${ }^{1}$, Yoichiro Ogawa ${ }^{1}$, Hiroshi Hasegawa ${ }^{1}$, \\ Tadayuki Kohda ${ }^{1}$ and Junzo Kamei ${ }^{2}$ \\ ${ }^{1}$ Central Research Laboratories, SSP Co., Ltd., Narita 286-8511, Japan \\ ${ }^{2}$ Department of Pathophysiology and Therapeutics, Faculty of Pharmaceutical Sciences, Hoshi, University, \\ 4-41, Ebara 2-chome, Shinagawa-ku, Tokyo 142-8501, Japan
}

Received July 27, 2001 Accepted November 21, 2001

\begin{abstract}
The effects of T-82 (2-[2-(1-benzylpiperidin-4-yl)ethyl]-2,3-dihydro-9-methoxy-1H-pyrrolo $[3,4-b]$ quinolin-1-one hemifumarate), a new quinoline derivative, on acetylcholinesterase (AChE) activity and acetylcholine $(\mathrm{ACh})$ release were compared with those of the well-known cholinesterase inhibitors tacrine and E2020. T-82, tacrine and E2020 all concentration-dependently inhibited AChE in rat brain homogenate $\left(\mathrm{IC}_{50 \mathrm{~s}}=109.4,84.2\right.$ and $11.8 \mathrm{nM}$, respectively). In addition, although tacrine strongly inhibited butyrylcholinesterase (BuChE), T-82 and E2020 showed only weak activity on BuChE in human plasma. In ex vivo experiments, intraperitoneal administration of T-82 at a dose of $30 \mathrm{mg} / \mathrm{kg}$ inhibited AChE activity in the hippocampus, frontal cortex and parietal cortex of rats. The effect of T-82 on the extracellular ACh concentration in rat brain was measured using in vivo microdialysis. T-82 at doses of 10 and $30 \mathrm{mg} / \mathrm{kg}$, i.p. increased the extracellular ACh concentration in the hippocampus and striatum in a dose-dependent manner. These findings suggest that T-82 activates the central cholinergic system by selectively inhibiting AChE activity, while weakly affecting peripheral BuChE activity, and that T-82 increases the extracellular ACh concentration in the brain, which is followed by inhibited AChE activity.
\end{abstract}

Keywords: Acetylcholinesterase inhibition, Acetylcholine release, Hippocampus, Striatum, In vivo microdialysis

Many factors have been suggested to cause Alzheimer's disease. Biochemical changes in the brains of Alzheimer's disease patients reflect reduced central cholinergic activity characterized by a decrease in choline acetyltransferase (ChAT) and acetylcholinesterase (AChE) activity $(1-3)$. The administration of muscarinic antagonist has caused amnesia in healthy volunteers (4). Thus, learning and memory processes are regulated by the central cholinergic system, and cholinomimetic replacement therapy may be able to relieve the cognitive loss associated with Alzheimer's disease. Since these discoveries, studies on cholinomimetic replacement therapy for Alzheimer's disease have sought novel cholinesterase inhibitors and muscarinic receptor agonists.

In an attempt to find a new type of $\mathrm{AChE}$ inhibitor that selectively inhibits AChE in the brain, we synthesized a novel molecule T-82 (2-[2-(1-benzylpiperidin-4-yl)ethyl]-

*Corresponding author. FAX: +81-476-26-7948

E-mail: Kazuo.Isomae@ssp.co.jp
2,3-dihydro-9-methoxy-1H-pyrrolo[3,4-b]quinolin-1-one hemifumarate) as shown in Fig. 1 . It contains an $N$-benzylalkylpiperidine moiety which is commonly present in other cholinesterase (ChE) inhibitors in more advanced stages of development; e.g., donepezil (E2020) (5) and TAK-147 (6).

In the present study, we examined the effects of T-82 on $\mathrm{AChE}$ activity in vitro and ex vivo. Furthermore, we investigated the effects of T-82 on acetylcholine (ACh) concentration in the brains of conscious, freely moving rats using a microdialysis procedure.

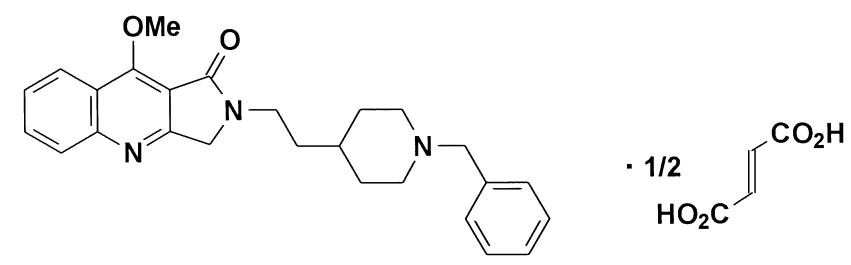

Fig. 1. Chemical structure of T-82. 


\section{MATERIALS AND METHODS}

\section{Animals}

Male Wistar rats $(5-11$ weeks) were purchased from Nihon SLC (Shizuoka) or Charles-River Japan, Inc. (Tsukuba). The animals were housed in a room controlled at $23 \pm 1{ }^{\circ} \mathrm{C}$ with $55 \pm 10 \%$ humidity and maintained under an alternating 12-h light/dark cycle (light automatically on at 7:00 A.M.). Food and water were given ad libitum.

\section{Drugs}

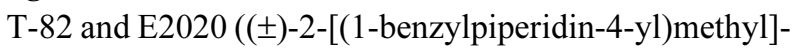
5,6-dimethoxy-indan-1-one hydrochloride) were synthesized at Central Research Laboratories, SSP Co., Ltd. (Narita). Tacrine (9-amino-1,2,3,4-tetrahydroacridine hydrochloride), acetylcholine perchlorate, choline chloride and physostigmine hemisulfate were purchased from Sigma Co. (St. Louis, MO, USA). All other chemicals were commercial products of reagent grade.

\section{Measurement of cholinesterase activity}

Animals were sacrificed by decapitation under ether anesthesia. The cerebral cortex was rapidly dissected on ice and then homogenized in $10 \mathrm{vol}$. of ice-cold $0.1 \mathrm{M}$ phosphate-buffered saline (PBS) ( $\mathrm{pH} \mathrm{8.0)} \mathrm{using} \mathrm{a} \mathrm{Teflon}$ homogenizer. The homogenate was centrifuged at $1,000 \times g$ for $10 \mathrm{~min}$ at $4^{\circ} \mathrm{C}$, and the supernatant was used as the source of AChE. AChE activity was determined using the method of Ellman et al. (7). A volume of $400 \mu \mathrm{L}$ of supernatant was added to a cuvette containing the following solutions: $2.55 \mathrm{~mL}$ of $0.1 \mathrm{M}$ PBS (pH 8.0), $100 \mu \mathrm{L}$ of $10 \mathrm{mM}$ dithiobisnitrobenzoic acid (DTNB) and $50 \mu \mathrm{L}$ of each test solution. After pre-incubation at $37^{\circ} \mathrm{C}$ for $4 \mathrm{~min}$, $20 \mu \mathrm{L}$ of $75 \mathrm{mM}$ acetylthiocholine was added as a substrate, and incubation was carried out at $37^{\circ} \mathrm{C}$ for $3 \mathrm{~min}$. Hydrolysis was accompanied by a continuous reaction between thiocholine and DTNB, which gave the rate of anion production, measured by absorbance at $412 \mathrm{~nm}$ in a spectrophotometer during a defined interval of time.

Inhibition of $\mathrm{AChE}$ and butyrylcholinesterase (BuChE) activities in peripheral tissues were determined as described above. AChE derived from bovine erythrocyte (Sigma) and BuChE derived from human plasma (Boehringer Mannheim, Germany) were assayed with $75 \mathrm{mM}$ acetylthiocholine iodide and $90 \mathrm{mM}$ butyrylthiocholine iodide as substrates, respectively.

\section{Ex vivo AChE activity}

Different doses of T-82, tacrine or E2020 were administered intraperitoneally. Five animals were used per treatment condition. Animals were killed by decapitation under ether anesthesia $1 \mathrm{~h}$ after each drug administration and the hippocampus, striatum, frontal cortex and parietal cortex were rapidly dissected on ice. AChE activities in these brain sections were assayed by the method described above.

\section{Microdialysis procedures}

Rats (body weight: $289-502$ g) were anesthetized with sodium pentobarbital ( $40 \mathrm{mg} / \mathrm{kg}$, i.p.) and placed in a stereotaxic frame (David Kopf Instruments, Tujunga, CA, USA). The skull was exposed and a stainless-steel guide cannula (AG-8; Eicom, Kyoto) was implanted in the hippocampus (A: $-5.3, \mathrm{~L}: 4.8, \mathrm{H}: 5.0 \mathrm{~mm}$ ) or striatum (A: 0.2, L: 3.0, $\mathrm{H}: 4.0 \mathrm{~mm}$ ) according to the atlas of Paxinos and Watson (8). From the next day after the operation, microdialysis probes with 3-mm-long cellulose membrane tubings (A-1-8-03, Eicom) were inserted into the hippocampus or striatum through the implanted guide cannula. The probes were perfused with Ringer's solution containing $0.1 \mu \mathrm{M}$ physostigmine in the hippocampus and striatum at a rate of $2 \mu \mathrm{L} / \mathrm{min}$, respectively. After more than $2 \mathrm{~h}$ of perfusion, when basal levels were stable, T-82, tacrine or E2020 dissolved in saline was injected i.p., and the effects of these drugs on the concentration of extracellular ACh were determined by collecting the perfusate for $3 \mathrm{~h}$ after drug administration.

\section{Measurement of ACh concentration}

The ACh concentration in brain microdialysates was determined by high-performance liquid chromatography (HPLC) (EP-300 and EP-1000, Eicom) with an electrochemical detector (ECD-300 and ECD-100, Eicom). Each dialysate was collected in a teflon microtube containing an appropriate amount of ethylhomocholine as an internal standard and dissolved in $25 \mathrm{mM}$ PBS ( $\mathrm{pH} 3.5$ ) with $10 \mathrm{mM}$ EDTA by an auto-sample injector with a $100-\mu \mathrm{L}$ sampling loop (AS-10, Eicom). Samples were injected into a column (Eicompak AC-GEL, $6.0 \times 150 \mathrm{~mm}$; Eicom) in which ACh was separated before entering an enzymereacting column (AC-Enzympak, Eicom) that contained immobilized AChE and choline oxidase which converted the ACh to hydrogen peroxide. The hydrogen peroxide was detected by a platinum electrode (WE-PT, Eicom) set at $450 \mathrm{mV}$. The mobile phase consisted of $100 \mathrm{mM}$ PBS ( $\mathrm{pH} 8.5$ ) containing $0.8 \mathrm{mM}$ sodium-1-decanesulfonate and $0.6 \mathrm{mM}$ tetramethylammonium chloride. The amount of ACh was calculated from the ratio of the peak height of ACh to that of ethylhomocholine.

\section{Measurement of hypothermia and salivation}

The rectal temperature of the rat was measured by a thermoprobe (Terumofiner CTM-303; Terumo, Tokyo) inserted into the rectum. The temperature was measured before and 15, 30, 60, 90, 120, 150 and $180 \mathrm{~min}$ after drug administration. 
Salivation was observed and scored essentially by the method of Rathbun and Slater (9) 15, 30, 60, 90, 120, 150 and $180 \mathrm{~min}$ after drug administration. Observations were scored as follows: 0, salivation does not exceed that in a normal rat; 1 , saliva is obvious around the teeth; 2 , saliva wets a narrow band around the mouth or wets the area under the jaw; and 3, saliva is dripping from the mouth. The maximum score in each rat was used as a measure of the drug effect.

\section{Statistical analyses}

ACh concentration was expressed as a percentage of the control $(100 \%)$ before the administration of drugs. The values shown in the figures are means \pm S.E.M. The mean values at each time after drug administration were compared with the control. Data analysis was performed using StatLight series software (Yukms Corp., Tokyo). Significant differences were determined by one-way analysis of variance (ANOVA) followed by Dunnett's test for multiple comparisons. Student's $t$-test or Aspin-Welch's $t$-test was used to evaluate differences between two groups. $P$-values less than 0.05 were considered significant.

\section{RESULTS}

\section{Inhibition of AChE and BuChE activity in vitro}

$\mathrm{T}-82$ potently inhibited the AChE activity of rat cerebral cortex extract in a concentration-dependent manner, with an $\mathrm{IC}_{50}$ value of $109.4 \mathrm{nM}$. T-82 was as potent as tacrine in the inhibition of AChE activity, and tenfold less potent than E2020 (Table 1).

As shown in Table 2, T-82 and E2020 very weakly inhibited BuChE activity in human plasma. The inhibitory activities of T-82 and E2020 on AChE were 322- and 1147-fold greater than their effects on $\mathrm{BuChE}$, respectively. However, tacrine inhibited $\mathrm{AChE}$ and $\mathrm{BuChE}$ nonselectively.

\section{Inhibition of AChE activities ex vivo}

Administration of T-82 at doses of 1 to $30 \mathrm{mg} / \mathrm{kg}$, i.p. inhibited AChE activity in the rat frontal cortex, parietal cortex, hippocampus and striatum in a dose-dependent manner (Table 3). Intraperitoneal administration of tacrine and E2020 also inhibited AChE activity in the rat frontal cortex, parietal cortex, hippocampus and striatum in a dose-dependent manner, at doses of 1 to $10 \mathrm{mg} / \mathrm{kg}$. In rat ex vivo experiments, the potency of $\mathrm{T}-82$ in the inhibition of AChE activity in various brain areas was lower than those of tacrine and E2020, as observed in the in vitro experiment.

Effects of T-82, tacrine and E2020 on the extracellular ACh concentration in the rat hippocampus

Effects of intraperitoneal administration of T-82, tacrine and E2020 on the extracellular ACh concentration in the hippocampus of rats are shown in Fig. 2. T-82 produced a dose-dependent increase in the extracellular ACh concentration at doses of 10 and $30 \mathrm{mg} / \mathrm{kg}$ (Fig. 2A). A significant increase in extracellular ACh was observed when $30 \mathrm{mg}$ $/ \mathrm{kg}$ of $\mathrm{T}-82$ was administered. The maximum extent of the increase produced by $30 \mathrm{mg} / \mathrm{kg}$ at $30 \mathrm{~min}$ after administration was $552 \%(P<0.01)$ of the pretreatment level. At this dose, the ACh-increasing action remained significant for $120 \mathrm{~min}$.

Tacrine at doses of 3 and $10 \mathrm{mg} / \mathrm{kg}$, i.p. dose-dependently and significantly increased the extracellular ACh concentration (Fig. 2B). The effect was maximum within $60 \mathrm{~min}$ after administration, and maximal ACh levels were $248 \%$ $(P<0.05)$ and $364 \%(P<0.01)$ of the pretreatment level, respectively. At the higher dose, the ACh-increasing action remained significant for $180 \mathrm{~min}$.

E2020 significantly increased the extracellular ACh concentration at doses of 3 and $10 \mathrm{mg} / \mathrm{kg}$, i.p. (Fig. 2C).

Table 2. Inhibitory effects of T-82 and reference compounds on $\mathrm{AChE}$ (bovine $\mathrm{RBC}$ ) and $\mathrm{BuChE}$ (human plasma) in vitro

\begin{tabular}{|c|c|c|c|}
\hline \multirow[b]{2}{*}{ Drug } & \multicolumn{2}{|c|}{$\mathrm{IC}_{50}(\mathrm{nM})$} & \multirow{2}{*}{$\begin{array}{c}\text { Ratio of } \mathrm{IC}_{50} \\
(\mathrm{BuChE} / \mathrm{AChE})\end{array}$} \\
\hline & AChE actibity & BuChE activity & \\
\hline $\mathrm{T}-82$ & $23 \pm 3$ & $7,400 \pm 999$ & 322 \\
\hline Tacrine & $132 \pm 22$ & $128 \pm 17$ & 0.97 \\
\hline E2020 & $15 \pm 2$ & $17,200 \pm 2,263$ & 1,147 \\
\hline
\end{tabular}

Each value represents the mean \pm S.E.M. of 3 experiments.

Table 1. Effects of T-82 and reference compounds on AChE activities in rat brain homogenate

\begin{tabular}{lrrrrrrrr}
\hline & \multicolumn{7}{c}{ Inhibition (\%) } & \\
\cline { 2 - 7 } & 1 & 3 & 10 & 30 & 100 & 300 & $1000 \mathrm{nM}$ & $\mathrm{IC}_{50}(\mathrm{nM})$ \\
\hline T-82 & & & & 25.1 & 47.6 & 72.8 & 89.2 & 109.4 \\
Tacrine & & 4.5 & 11.5 & 20.8 & 47.8 & 72.3 & 89.7 & 84.2 \\
E2020 & 9.7 & 16.3 & 47.0 & 70.5 & 88.9 & & & 11.8 \\
Physostimine & & & 7.7 & 24.5 & 62.2 & 88.2 & & 65.2 \\
\hline
\end{tabular}

Each $\mathrm{IC}_{50}$ value was calculated by the probit method. 
Table 3. Effects of $\mathrm{T}-82$ and other $\mathrm{ChE}$ inhibitors on AChE activities in various brain regions

\begin{tabular}{|c|c|c|c|c|c|c|}
\hline \multirow{2}{*}{ Drugs } & \multirow{2}{*}{$\begin{array}{c}\text { Dose } \\
\text { (mg/kg, i.p.) }\end{array}$} & \multirow{2}{*}{$\mathrm{N}$} & \multicolumn{4}{|c|}{ AChE activities $\left(\mathrm{nmol} \cdot \mathrm{min}^{-1} \cdot \mathrm{mg}\right.$ protein $\left.{ }^{-1}\right)$} \\
\hline & & & Frontal cortex & Parietal cortex & Hippocampus & Striatum \\
\hline Control & & 5 & $15.2 \pm 0.5$ & $15.8 \pm 0.6$ & $28.8 \pm 1.2$ & $78.2 \pm 3.6$ \\
\hline \multirow[t]{4}{*}{$\mathrm{T}-82$} & 1.0 & 5 & $16.0 \pm 0.3$ & $14.9 \pm 0.2$ & $27.0 \pm 1.2$ & $76.1 \pm 0.6$ \\
\hline & 3.0 & 5 & $14.7 \pm 0.6$ & $13.3 \pm 0.6$ & $25.2 \pm 0.9$ & $70.9 \pm 2.7$ \\
\hline & 10.0 & 5 & $14.5 \pm 0.4$ & $13.0 \pm 0.3^{*}$ & $25.8 \pm 1.0$ & $68.9 \pm 1.0$ \\
\hline & 30.0 & 5 & $12.9 \pm 0.9 *$ & $13.1 \pm 1.1$ & $24.0 \pm 0.9^{*}$ & $64.9 \pm 3.4^{*}$ \\
\hline \multirow[t]{3}{*}{ Tacrine } & 1.0 & 5 & $12.5 \pm 0.8$ & $12.9 \pm 1.0$ & $25.7 \pm 2.0$ & $75.2 \pm 4.8$ \\
\hline & 3.0 & 5 & $13.8 \pm 0.5$ & $13.2 \pm 0.3$ & $25.4 \pm 1.0$ & $71.8 \pm 2.8$ \\
\hline & 10.0 & 5 & $10.4 \pm 1.0 * *$ & $10.3 \pm 1.2^{*}$ & $22.1 \pm 1.8^{*}$ & $62.5 \pm 5.3^{*}$ \\
\hline \multirow[t]{3}{*}{ E2020 } & 1.0 & 5 & $12.7 \pm 0.7$ & $12.2 \pm 0.5$ & $23.7 \pm 1.7$ & $73.2 \pm 3.7$ \\
\hline & 3.0 & 5 & $10.8 \pm 1.0$ & $10.2 \pm 0.8^{*}$ & $18.7 \pm 1.1 * *$ & $59.9 \pm 3.8 * *$ \\
\hline & 10.0 & 5 & $6.8 \pm 0.1 * *$ & $6.9 \pm 0.1 * *$ & $12.0 \pm 0.7 * *$ & $33.2 \pm 1.6 * *$ \\
\hline
\end{tabular}

Each value represents the mean \pm S.E.M. of 5 animals. Significantly different from the control $(* P<0.05, * * P<0.01)$.

The maximum increases produced by these doses within 60 min after administration were $240 \% \quad(P<0.05)$ and $516 \%(P<0.01)$, respectively. At the higher dose, the AChincreasing action remained significant for $180 \mathrm{~min}$.

Effects of T-82, tacrine and E2020 on the extracellular ACh concentration in the rat striatum

Effects of intraperitoneal administration of T-82, tacrine and E2020 on the extracellular ACh concentration in the striatum of rats are shown in Fig. 3. T-82 produced a dosedependent increase in the extracellular ACh concentration in the striatum at doses of 10 and $30 \mathrm{mg} / \mathrm{kg}$ (Fig. 3A). A significant increase in extracellular $\mathrm{ACh}$ was produced by $\mathrm{T}-82$ at a dose of $30 \mathrm{mg} / \mathrm{kg}$. The maximum extent of the increase produced by $30 \mathrm{mg} / \mathrm{kg}$ at $30 \mathrm{~min}$ after administration was $369 \%(P<0.01)$ of the pretreatment level. At this dose, the ACh-increasing action remained significant for $180 \mathrm{~min}$.

Tacrine at a dose of $1 \mathrm{mg} / \mathrm{kg}$ had no effect on the extracellular ACh concentration in the striatum, while it had a significant effect at $3 \mathrm{mg} / \mathrm{kg}$, i.p. (Fig. 3B). The effect was maximum within $30 \mathrm{~min}$ after administration, and maximal ACh levels were $255 \%(P<0.01)$ of the pretreatment level. At the higher dose, the ACh-increasing action remained significant for $105 \mathrm{~min}$.

E2020 at $1 \mathrm{mg} / \mathrm{kg}$, i.p. significantly increased the ACh concentration in the striatum. The maximum increase produced by this dose within $30 \mathrm{~min}$ after administration was 189\% $(P<0.01)$. At a higher dose, the ACh-increasing action remained significant for $180 \mathrm{~min}$.

Effects of T-82, tacrine and E2020 on body temperature and salivation

The time course of hypothermia induced by T-82, tacrine and E2020 is shown in Fig. 4A. Administration of tacrine or E2020 at a dose of $10 \mathrm{mg} / \mathrm{kg}$, i.p. caused significant hypothermia in rats. Hypothermia induced by tacrine and E2020 reached a maximum 60 or 90 min after administration and continued over $150 \mathrm{~min}$. However, administration of $\mathrm{T}-82$, even at a higher dose $(30 \mathrm{mg} / \mathrm{kg}$, i.p. $)$, had no significant hypothermic effect in rats.

The time course of the salivation score induced by T-82, tacrine and E2020 is shown in Fig. 4B. Salivation induced by tacrine or E2020 at a dose of $10 \mathrm{mg} / \mathrm{kg}$, i.p. reached a maximum $15 \mathrm{~min}$ after administration and disappeared within $180 \mathrm{~min}$ after administration. However, administration of T-82, even at a higher dose $(30 \mathrm{mg} / \mathrm{kg}$, i.p. $)$, did not produce obvious salivation in rats.

\section{DISCUSSION}

In vitro studies showed that although it was less potent than E2020, T-82 strongly inhibited AChE activity. Furthermore, T-82 inhibited AChE activity almost as strongly as tacrine. T-82 and E2020 were highly selective for $\mathrm{AChE}$ over BuChE, in excess of 3 and 10 orders of magnitude, respectively, whereas tacrine did not show similar selective activity. Tacrine has been reported to inhibit AChE and to produce mixed inhibition of ChE (10). Moreover, E2020 has been reported to be more potent than tacrine at inhibiting $\mathrm{AChE}$ (5). The present finding that the potency of E2020 at inhibiting AChE was about ninefold higher than that of tacrine is consistent with previous findings $(5,11)$. Taken together, these results suggest that although its potency is relatively low, the inhibitory profiles of T-82 on AChE activity are similar to those of E2020.

It has been reported that local ChE inhibitor application 

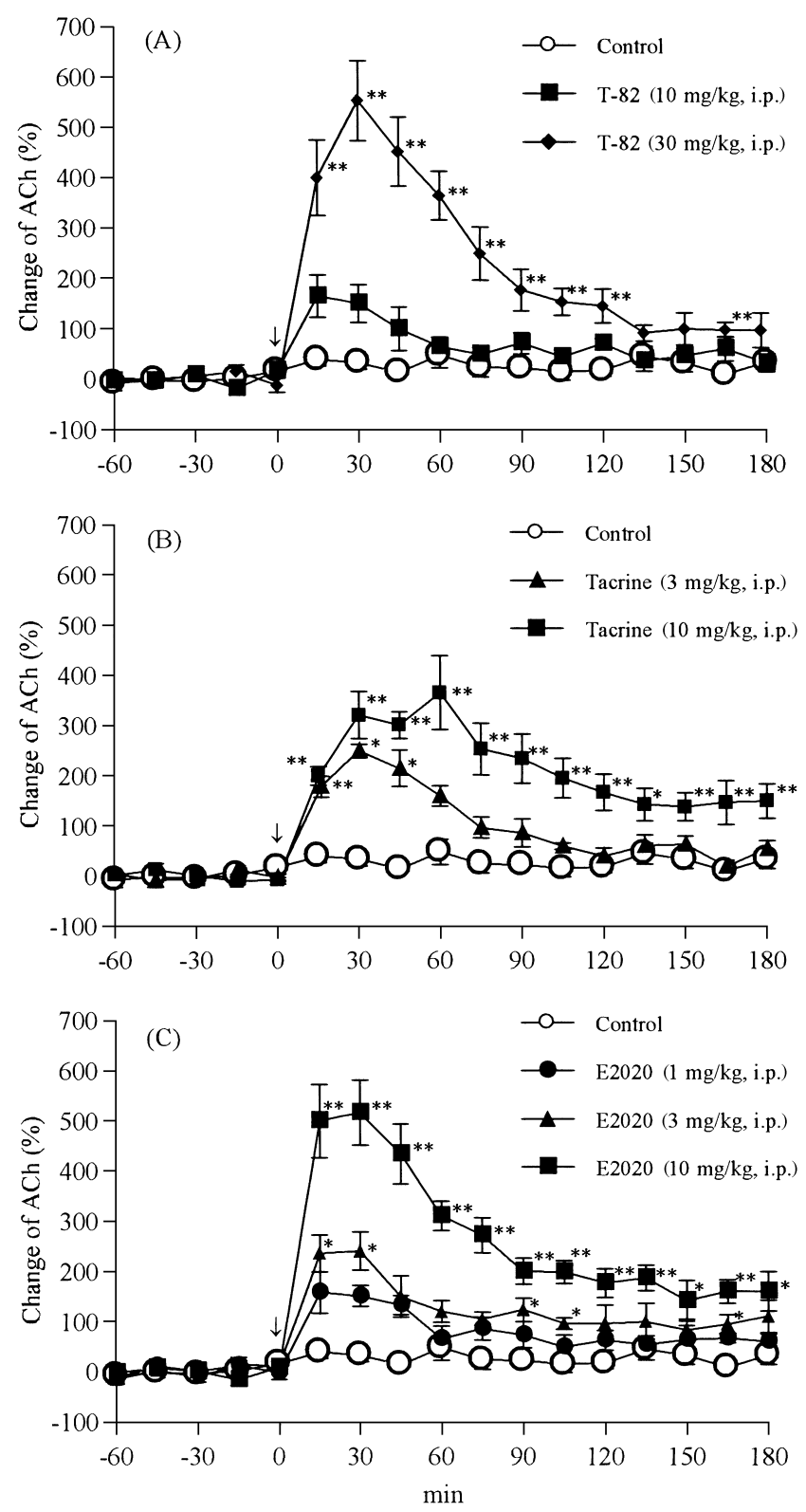

Fig. 2. Effects of T-82 (A), tacrine (B) and E2020 (C) on extracellular levels of ACh in microdialysis samples from the hippocampus of conscious, freely moving rats. Each drug was administered at $0 \min (\downarrow)$. Control animals were injected with saline (i.p.). Basal concentration of ACh $(155 \pm 6 \mathrm{fmol})$ was detected in the perfusates collected with physostigmine $\left(10^{-7} \mathrm{M}\right)$, at 15 -min intervals. Each symbol with a vertical bar represents the mean with S.E.M. $(n=6)$. ${ }^{*} P<0.05,{ }^{*} P<0.01$ vs control.

via a microdialysis probe to increase the concentration of $\mathrm{ACh}$ in the perfusate to a detectable level can interfere with the effects of systemically administered $\mathrm{ChE}$ inhibitors (12). In those experiments, however, relatively high concentrations $(5-50 \mu \mathrm{M})$ of physostigmine were added to the perfusion solution. Meanwhile, we used a low concentration of physostigmine $(0.1 \mu \mathrm{M})$ in this study in
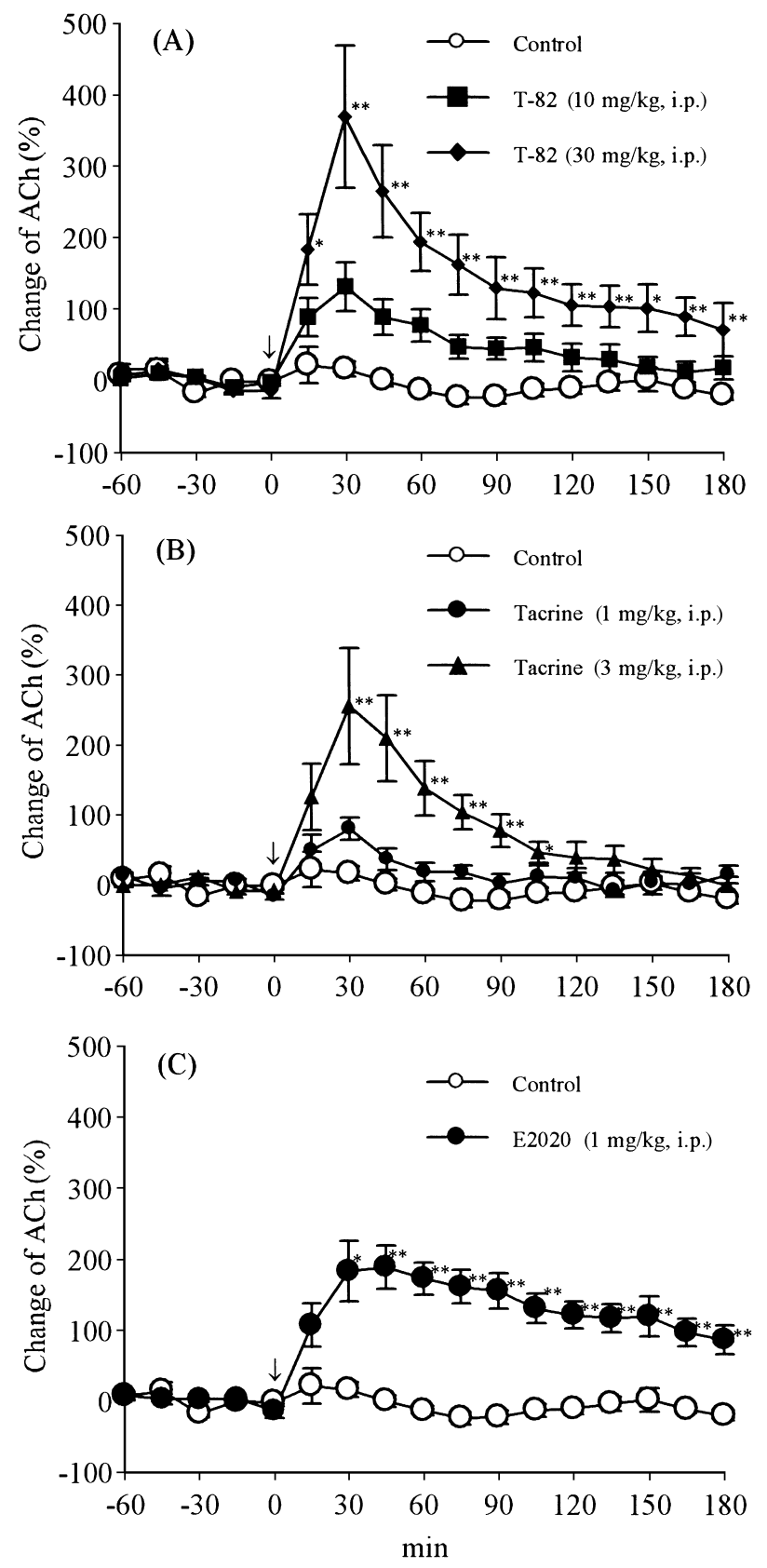

Fig. 3. Effects of T-82 (A), tacrine (B) and E2020 (C) on extracellular levels of $\mathrm{ACh}$ in microdialysis samples from the striatum of conscious, freely moving rats. Each drug was administered at 0 min $(\downarrow)$. Control animals were injected with saline (i.p.). Basal concentration of ACh $(260 \pm 22 \mathrm{fmol})$ was detected in the perfusates collected with physostigmine $\left(10^{-7} \mathrm{M}\right)$, at 15 -min intervals. Each symbol with a vertical bar represents the mean with S.E.M. $(n=4-6)$. ${ }^{*} P<0.05,{ }^{* *} P<0.01$ vs control.

order to minimize the influence of the local $\mathrm{ChE}$ inhibitor on the effect of systemically administered $\mathrm{ChE}$ inhibitor while still increasing the concentration of $\mathrm{ACh}$ in the perfusate to a detectable level.

Systemic administration of T-82 (10 and $30 \mathrm{mg} / \mathrm{kg}$, i.p.) 

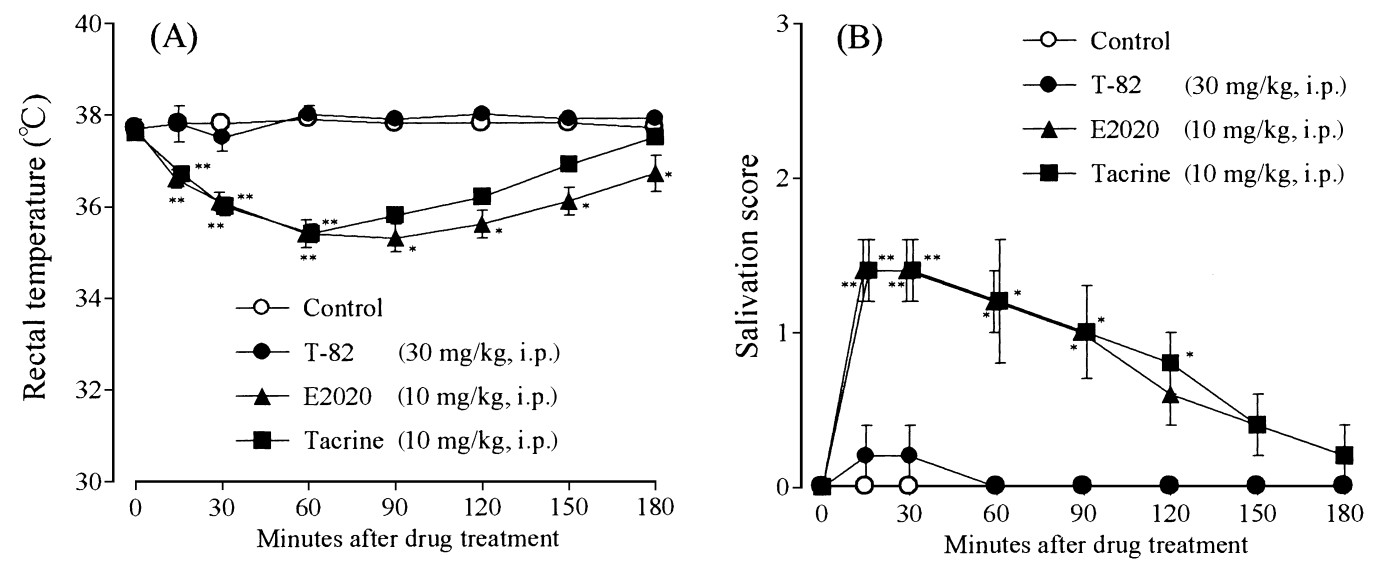

Fig. 4. Effects of T-82, tacrine and E2020 on rectal temperature (A) and salivation (B) in rats. Each symbol with a vertical bar represents the mean with S.E.M. $(\mathrm{n}=5)$. Significantly different from the control $(* P<0.05, * * P<0.01)$.

dose-dependently increased the extracellular concentration of $\mathrm{ACh}$ in the hippocampus and the striatum of the rat. Since T-82 selectively inhibited AChE activity in rat brain in vitro and ex vivo, this inhibitory effect on AChE activity may be responsible for the increase in the extracellular ACh concentration. In the present study, we also evaluated the effects of tacrine and E2020 on the extracellular ACh concentration in the hippocampus and striatum. Intraperitoneal administration of each drug also increased the extracellular concentration of $\mathrm{ACh}$. The minimum effective doses of $\mathrm{T}-82$, tacrine and $\mathrm{E} 2020$ were 30,3 and $3 \mathrm{mg} / \mathrm{kg}$ in the hippocampus and 30,3 and $1 \mathrm{mg} / \mathrm{kg}$ in the striatum, respectively. At doses similar to those used in the present study, tacrine and E2020 have been shown to have some beneficial effects on learning and memory in animal models with impaired cholinergic functions $(13,14)$. These findings suggest that an increase in the ACh concentration in the synaptic clefts of neurons in the hippocampus and striatum may contribute, at least in part, to the improvement of memory and learning induced by tacrine or E2020. Thus, an increase in the ACh concentration in the synaptic clefts of the neurons in the hippocampus and striatum following the selective inhibition of AChE activity suggests that T-82 may ameliorate impaired learning and memory. On the other hand, although T-82 was as potent as tacrine in the inhibition of AChE activity in vitro, it was not as strong as tacrine at increasing the extracellular ACh concentration in the brain. Although the detailed mechanism of this discrepancy is not clear, it is possible that a higher permeability of the blood-brain barrier for tacrine than T-82 might contribute to this unexpected observation.

It is well known that central cholinergic neurons play an important role in learning and memory $(15,16)$. In particular, dysfunction of central cholinergic neurotransmission has been reported in patients with amnesia symptoms such as Alzheimer's disease and senile dementia. For example, marked degeneration of cholinergic neurons in the nucleus basalis of Meynert and decreased ChAT activity in the cerebral cortex have been found in the postmortem brains of patients with Alzheimer's disease $(2,17-19)$. Therefore, drugs that activate central cholinergic neurotransmission may be effective for treating amnesia symptoms. In fact, AChE inhibitors, such as tacrine and E2020, are thought to augment cholinergic neurotransmission by preventing the hydrolysis of extracellular ACh $(20,21)$. These compounds have been reported to improve the cognitive dysfunction in patients with Alzheimer's disease $(22-24)$ and in animal models of amnesia $(20,25,26)$. On the other hand, tremor, hypothermia, hypersalivation, chewing and yawning induced by muscarinic agonists are well-recognized central or peripheral cholinomimetic side effects $(27-29)$. It has been reported that tacrine causes serious side effects in humans $(30,31)$ and animals $(20,32)$. In the present study, although E2020 and tacrine increased the ACh concentration more potently than T-82 in the rat hippocampus and striatum, these drugs also produced cholinomimetic symptoms, such as hypothermia and hypersalivation. However, we demonstrated that T-82 at a dose of $30 \mathrm{mg} / \mathrm{kg}$, i.p., which produced a significant increase in the ACh concentration in the hippocampus and striatum following the selective inhibition of AChE activity, did not produce any cholinomimetic symptoms. Based on these results, it is possible that T-82 may be effective for the treatment of amnesia symptoms, such as in Alzheimer's disease and senile dementia, and with few side effects.

In conclusion, the present findings demonstrate that T-82 selectively inhibits AChE activity in vitro and ex vivo and increases the extracellular ACh concentration in the brain, especially in the hippocampus of rats. Furthermore, these pharmacological profiles suggest that T-82 may be able to ameliorate impaired learning and memory, and this drug may be useful in the treatment of Alzheimer's disease. 


\section{REFERENCES}

1 Bowen DM, Spillane JA, Curzon G, Meier-Ruge W, White P, Iwan-goff $\mathrm{P}$ and Davison AN: Accelerated aging or selective neuronal loss as an important cause of dementia? Lancet 1(8106), 11 - 14 (1979)

2 Davies P and Maloney AJF: Selective loss of central cholinergic neurons in Alzheimer's disease. Lancet 2(8000), 1403 (1976)

3 Whitehouse PJ, Price DL, Struble RG, Clark AW and DeLong MR: Alzheimer's Disease and senile dementia; Loss of neurons in the basal forebrain. Science 215, 1237 - 1239 (1982)

4 Drachman DA and Leavitt J: Human memory and the cholinergic system. A relationship to aging? Arch Neurol 30, 113 121 (1974)

5 Sugimoto H, Iimura Y, Yamanishi Y and Yamatsu K: Synthesis and structure-activity relationships of acetylcholinesterase inhibitors: 1-benzyl-4-[(5,6-dimethoxy-1-oxoindan-2-yl)methyl] piperidine hydrochloride and related compounds. J Med Chem 38, 4821 - 4829 (1995)

6 Ishihara Y, Hirai K, Miyamoto M and Goto G: Central cholinergic agents. 6. Synthesis and evaluation of 3-[1-(phenylmethyl)-4-piperidinyl]-1-(2,3,4,5-tetrahydro-1H-1-benzazepine8-yl)-1-propanones and their analogs as central selective acetylcholinesterase inhibitors. J Med Chem 37, 2292 - 2299 (1994)

7 Ellman GL, Courtney KD, Andres V and Featherstone RM: A new and rapid colorimetric determination of acetylcholinesterase activity. Biochem Pharmacol 7, 88 - 95 (1961)

8 Paxinos G and Watson C: The Rat Brain in Stereotaxic Coordinates, 2nd ed, Academic Press, San Diego (1986)

9 Rathbun RC and Slater LH: Amitriptyline and nortriptyline as antagonists of central and peripheral cholinergic activation. Psychopharmacologia (Berl) 4, 114 - 125 (1963)

10 Berman HA and Leonard K: Interaction of tetrahydroaminoacridine with acetylcholinesterase and butyrylcholinesterase. Mol Pharmacol 41, 412 - 418 (1991)

11 Kojima J, Nakajima K, Ochiai M and Nakayama K: Effects of NIK-247 on cholinesterase and scopolamine-induced amnesia. Methods Find Exp Clin Pharmacol 19, 245 - 251 (1997)

12 Messamore E, Ogane N and Giacobini E: Cholinesterase inhibitor effects on extracellular acetylcholine in rat striarum. Neuropharmacology 32, 291 - 296 (1993)

13 Nabeshima T, Maruyama E, Katoh A and Kameyama T: The effect of tacrine (THA) on cycloheximide- and basal forebrain lesion-induced memory deficit in rats. Jpn J Pharmacol 57, $311-319(1991)$

14 Wang T and Tang XC: Reversal of scopolamine-induced deficits in radial maze performance by (-)-huperzine A: comparison with E2020 and tacrine. Eur J Pharmacol 349, 137 - 142 (1998)

15 Winkler J, Suhr ST, Gage FH, Thul LJ and Fisher LJ: Essential role of neocortical acetylcholine in spatial memory. Nature 375, $484-487$ (1995)

16 Smith G: Animal models of Alzheimer's disease: Experimental cholinergic denervation. Brain Res Rev 13, 103 - 118 (1988)

17 Drachman DA: Memory and cognitive function in man: Does the cholinergic system have a specific role? Neurology 27, 783 - 790 (1977)

18 Perry EK, Perry RH, Blessed G and Tomlinson BE: Necropsy evidence of central cholinergic deficits in senile dementia. Lancet 1(8004), 189 (1977)
19 White P, Hiley CR, Goodhardt MJ, Carrasco LH, Keet JP and Williams IEI: Neocortical cholinergic neurons in elderly people. Lancet 1(8013), 668 - 671 (1977)

20 Nielsen JA, Mena EE, Williams IH, Nocerini MR and Liston D: Correlation of brain levels of 9-amino-1,2,3,4-tetrahydroaminoacridine (THA) with neurochemical and behavioral changes. Eur J Pharmacol 173, 53 - 64 (1989)

21 Kawashima K, Sato A, Yoshizawa M, Fujii T, Fujimoto K and Suzuki T: Effects of the centrally acting cholinesterase inhibitors tetrahydroaminoacridine and E2020 on the basal concentration of extracellular acetylcholine in the hippocampus of freely moving rats. Naunyn Schmiedebergs Arch Pharmacol 350, $523-528$ (1994)

22 Summers WK, Majovski LV, Marsh GM, Tachiki K and Kling A: Oral tetrahydroaminoacridine in long-term treatment of senile dementia, Alzheimer type. N Engl J Med 315, 1241 1245 (1986)

23 Davis KL, Thal LJ, Gamzu ER, Davis CS, Woolson RF, Gracon SI, Frachman DA, Schneider L, Whitehouse PJ, Hoover TM, Morris JC, Kawas CH, Knopman DS, Earl NL, Kumar V, Doody RS and The tacrine collaborative study group: A double-blind, placebo-controlled multicenter study of tacrine for Alzheimer's disease. N Engl J Med 327, 1253 - 1259 (1992)

24 Rogers SL, Friedhoff LT and the Donepezil study group: The efficacy and safety of donepezil in patients with Alzheimer's disease: results of US multicentre, randomized, double-blind, placebo-controlled trial. Dementia 7, 293 - 303 (1996)

25 Matsuno K, Senda T, Matsunaga K and Mita S: Ameliorating effects of $\sigma$ receptor ligands on the impairment of passive avoidance tasks in mice: Involvement in the central acetylcholinergic system. Eur J Pharmacol 261, 43 - 51 (1994)

26 Poorheidari G, Stanhope KJ and Pratt JA: Effects of the potassium channel blockers, apamin and 4-aminopyridine, on scopolamine-induced deficits in the delayed matching to position task in rats: a comparison with the cholinesterase inhibitor E2020. Psychopharmacology (Berl) 135, 242 - 255 (1998)

27 Spencer PSJ: Activity of centrally acting and other drugs against tremor and hypothermia induced in mice by tremorine. Br J Pharmacol 25, 442 - 455 (1965)

28 Palacios JM, Bollinger G, Closse A, Enz A, Gmelin G and Malanowski J: The pharmacological assessment of RS-86 (2-ethyl-2,8-diazaspiro-[4,5]-decan-1,3-dion hydrobromide). A potent, specific muscarinic acetylcholine receptor agonist. Eur J Pharmacol 125, 45 - 62 (1986)

29 Ushijima I, Yamada K, Inoue T, Tokunaga T, Fukukawa T and Noda Y: Muscarinic and nicotinic effects on yawning and tongue protruding in the rat. Pharmacol Biochem Behav 21, $297-300$ (1984)

30 Forsyth DR, Surmon DJ, Morgan RA and Wilcock GK: Clinical experience with and side-effects of tacrine hydrochloride in Alzheimer's disease: A pilot study. Age Aging 18, 223-229 (1989)

31 Ott BR and Lannon MC: Exacerbation of parkinsonism by tacrine. Clin Neuropharmacol 15, 322 - 325 (1992)

32 Yoshida S and Suzuki N: Antiamnesic and cholinomimetic side-effects of the cholinesterase inhibitors, physostigmine, tacrine and NIK-247 in rats. Eur J Pharmacol 250, 117-124 (1993) 